(Jurnal Teknologi Komputer dan Sistem Informasi)

Februari 2021, Vol 1, No 1, Hlm. 13-18

Available online at http://jurnal.goretanpena.com/index.php/teknisi

\title{
IMPLEMENTASI TEKNIK COUNTER PADA AIR MANCUR UNTUK MEMBUAT ANIMASI AIR BERBASIS MIKROKONTROLER ATMEGA 16
}

\author{
Candra Cahaya Utama ${ }^{1}$, Trinanda Syahputra ${ }^{2}$, Mochammad Iswan ${ }^{3}$ \\ STMIK Triguna Dharma, Medan \\ e-mail: candracu22@gmail.com
}

\begin{abstract}
Water Fountain is one of the ornaments in the house yard. Most fortains in general have mediocre variations, only emitting water that gushes upwards, thus reducing the beauty and making it less attractive. The automatic system design and construction system in automatic fountain animation can be set and pragrammed in the microcontroller. A microcontroller is a chip that can digitally process data in accordance with programming commands. In this system, it will develop a fountain that can produce animations at each burst of water to become a additional attraction for the community. The control system used in a timer counter control system that is implementede in a fountain
\end{abstract}

Keywords: Air Mancur, Timer/Counter. Mikrokontroler

\begin{abstract}
Abstrak: Air mancur merupakan salah satu penghias dipekarangan rumah. Kebanyakan air mancur pada umumnya yang memiliki variasi biasa-biasa saja, hanya mengeluarkan air yang menyembur ke atas saja sehingga mengurangi keindahan dan membuat kurang menarik perhatian. Sistem rancang bangun system otomatis pada animasi air mancur otomatis dapat diatur dan diprogram didalam Mikrokontroller. Mikrokontroller adalah sebuah Chip yang dapat melakukan pemrosesan data secara digital sesuai dengan perintah pemrograman. Dalam sistem ini akan mengembangkan sebuah air mancur yang dapat mengeluarkan animasi-animasi di setiap semburan airnya untuk menjadi tambahan daya tarik bagi masyarakat. Sistem kendali yang digunakan merupakan sistem kendali Timer Counter yang di implementasikan di air mancur.
\end{abstract}

Kata kunci: Air Mancur, Timer/Counter. Mikrokontroler

\section{PENDAHULUAN}

Air mancur merupakan sebuah aliran air yang menyebar secara diagonal dari sebuah sumber. salah satu penghias dipekarangan rumah, yang membuat masyarakat senang melihatnya. Oleh karena sifatnya yang membuat masyarakat senang melihatnya, maka air mancur dikatagorikan sebagai salah satu penghias dipekarangan rumah [1].

Salah satu jenis air mancur yang sering dibuat dipekarangan rumah adalah air mancur bias berupa air mancur tembok atau berdiri sendiri, air mancur dapat dibuat didalam berbagai wadah seperti batu, beton, atau logam. Dalam kehidupan modern seperti sekarang ini air mancur merupakan bagian dari penghias dipekarangan rumah yang menjadi daya tarik karena dapat memberikan suasana menjadi lebih indah untuk dipandang. Kebanyakan air mancur pada umumnya yang memiliki variasi biasa-biasa saja, hanya mengeluarkan air yang menyembur ke atas saja sehingga mengurangi keindahan dan membuat kurang menarik perhatian masyarakat. 


\section{(Jurnal Teknologi Komputer dan Sistem Informasi)}

Februari 2021, Vol 1, No 1, Hlm. 13-18

Available online at http://jurnal.goretanpena.com/index.php/teknisi

Fungsi awal dari air mancur saat itu adalah sebagai sumber air untuk kegunaan sehari-hari bagi masyarakat suatu kota atau pedesaan. Saat itu sumber air untuk air mancur selalu pada posisi yang lebih tinggi sehingga air mancur dihasilkan dengan gaya gravitasi.

Dalam sistem ini akan mengembangkan sebuah air mancur yang dapat mengeluarkan animasi-animasi disetiap semburan airnya untuk menjadi tambahan daya tarik bagi masyarakat. Sistem kendali yang digunakan merupakan sistem kendali timer counter yang diimplementasikan diair mancur. Oleh karena itu dibuatlah alat untuk membuat animasi air mancur otomatis dengan menggunakan teknik counter berbasis mikrokontroler atmega 16 .

\section{Air Mancur}

Air mancur adalah semburan cairan yang menyembur ke atas karena tekanan yang diberikan padanya dari pipa atau jenis lubang lainnya . Air menjadi bagian yang tidak terpisahkan dari kehidupan manusia bagaikan sumber kehidupan yang memberikan ketenangan batin dan menyejukkan. Air mancur merupakan bagian salah satu bentuk keberadaan elemen air.

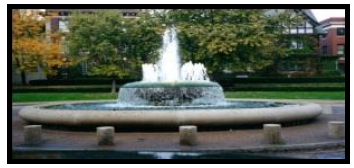

Gambar . Air Mancur

\section{Mikrokontroler Atmega 16}

Mikrokontroler atau pengendali mikro adalah sebuah komputer kecil ("Special Purpose Computer") di dalam sebuah IC/chip. Dalam sebuah IC/chip mikrokontroler terdapat CPU, memori, timer, saluran komunikasi serial dan parallel, port input/output, ADC, dll. Mikrokontroler digunakan sebagai pengendali yang mengatur semua proses

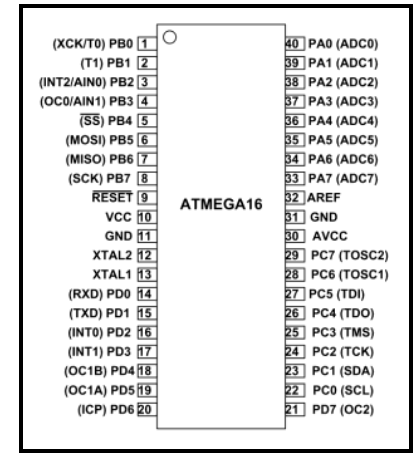

Gamabar .Atmega 16

\section{Pompa Air DC}

Pompa DC adalah suatu perangkat elektronika yang dapat digunakan untuk mengirim sebuah cairan dari suatu tempat yang ingin dituju melalui suatu kontruksi dengan cara menambahkan energy pada cairan yang akan di alirkan ke tempat tujuan secara terus menerus. Pompa Dc beroperasi dengan prinsip membuat perbedaan tekanan antara bagian masuk (suction) dengan bagian keluar (discharge).

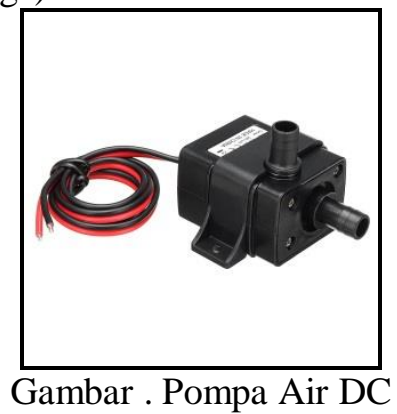

elay

Relay adalah Saklar (Switch) yang dioperasikan secara listrik dan merupakan komponen Electromechanical (Elektromekanikal) yang terdiri dari 2 bagian utama yakni Elektromagnet (Coil) dan Mekanikal (seperangkat Kontak Saklar/Switch) . Relay menggunakan Prinsip Elektromagnetik untuk menggerakkan Kontak Saklar sehingga dengan arus listrik yang kecil (low power) dapat menghantarkan listrik yang bertegangan lebih tinggi 
Februari 2021, Vol 1, No 1, Hlm. 13-18

Available online at http://jurnal.goretanpena.com/index.php/teknisi

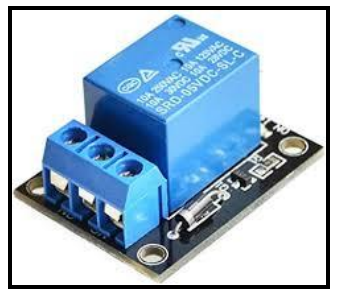

Gambar .Relay

\section{LED (Light Emiting Diode)}

LED (Light Emiting Diode) adalah suatu semikonduktor yang memancarkan cahaya monokromatik yang tidak koheren ketika diberi tegangan maju/searah [5]. Untuk menyalakan LED, cukup dengan mengalirkan arus dari anoda ke katoda dengan beda potensial minimum berkisar 1,5 sampai 2 Volt dan arusnya berkisar 20 Ma .

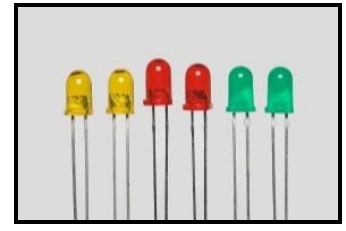

\section{Gambar LED (Light Emiting Diode)}

\section{LCD (Liquid Crystal Display) 16x2}

Display elektronik adalah salah satu komponen elektronika yang berfungsi sebagai tampilan suatu data, baik karakter, huruf ataupun grafik. LCD (Liquid Cristal Display) adalah salah satu jenis display elektronik yang dibuat dengan teknologi CMOS logic yang bekerja dengan tidak menghasilkan cahaya tetapi memantulkan cahaya yang ada di sekelilingnya terhadap front-lit atau mentransmisikan cahaya dari back-lit [7].

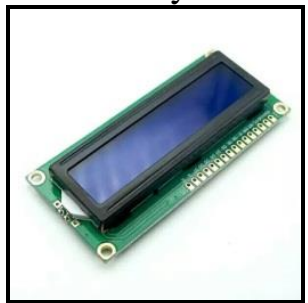

Gambar LCD (Liquid Cristal Display)

\section{LDR (Light Dependent Resistor)}

LDR (Light Dependent Resistor) adalah komponen elektronika yang pada dasarnya mempunyai sifat yang sama dengan resistor, hanya saja nilai resistansi dari LDR berubah-ubah sesuai dengan tingkat intensitas cahaya yang diterimanya. LDR merupakan sensor yang bekerja apabila terkena cahaya. LDR memiliki hambatan yang sangat tinggi jika tidak terkena cahaya dan memiliki hambatan yang sangat kecil jika terkena cahaya.

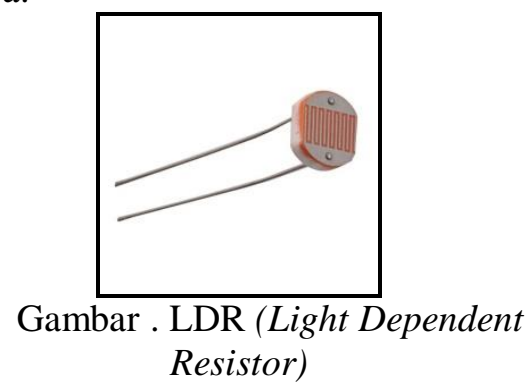

\section{METODE}

$\begin{array}{llr} & \text { Pada penelitian ini digunakan } \\ \text { metode yang diterapkan } & \text { untuk } \\ \text { penyelesaian permasalahan } & \text { dalam }\end{array}$ mengimplementasikan kecerdasan buatan secara sistematis untuk perancangan yang akan dibuat pada Implementasi Teknik Counter pada air mancur untuk membuat animasi air berbasis Mikrokontroler Atmega 16. Metode penelitian yang menggunakan teknik sebagai berikut :

Adapun metodologi penelitian yang di terapkan mahasiswa dalam penelitian ini sebagai berikut :

1. Percobaan Langsung

Percobaan-percobaan pada peenyesuaian Timer Counter sebagai input serta pompa DC dan LED sebagai output berdasarkan kebutuhan, apabila mengalami masalah atau kendala-kendala maka akan langsung di perbaiki agar sistem bekerja dengan baik sesuai dengan yang dibutuhkan.

\section{Studi Literatur}

Pada metode ini pembelajaran konsep dasar tentang komunikasi serial, datasheet mikrokontroler, datasheet sensor LDR, 


\section{(Jurnal Teknologi Komputer dan Sistem Informasi)}

Februari 2021, Vol 1, No 1, Hlm. 13-18

Available online at http://jurnal.goretanpena.com/index.php/teknisi

artikel sebagai referensi yang berkaitan dengan pembahasan.

3. Pengamatan Langsung

Pada metode ini dilakukan dengan pengamatan langsung pada sistem yang bekerja, mencatat, melakukan perhitungan langsung pada objek yang diteliti dan di tarik kesimpulan untuk perbaikan sistem.

\section{HASIL DAN PEMBAHASAN}

Dalam perancangan sistem elektronik dikerjakan dalam beberapa rangkaian yang akan menjadi satukesatuan sistem. Beberapa rangkaian sistem antara lain :

\section{Rangkaian Pompa Air ke Mikrokontroler Atmega 16}

Berikut ini adalah gambar rangkaian pompa Air yang dapat dilihat pada gambar sebagai berikut :

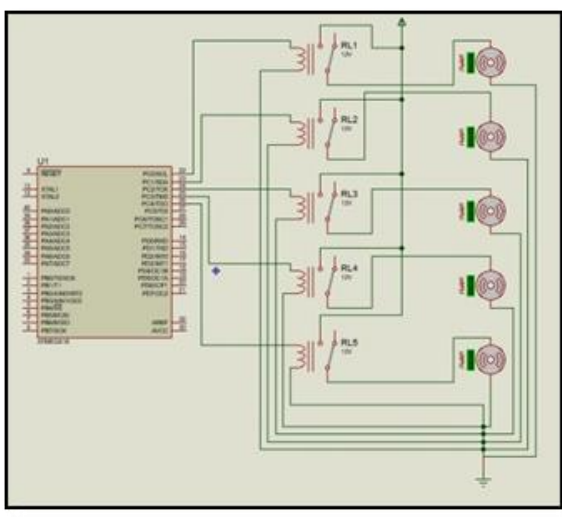

Gambar Rangkaian Pompa Air

Pada rangkaian diatas menjelaskan rangkaian pompa Air. Rangkaian ini menggunakan 6 pompa air DC $12 \mathrm{~V}$ yang dihubungkan ke Mikrokontroler Atmega 16.

2. Rangkaian Relay ke Mikrokontroler Atmega 16

Berikut ini adalah gambar rangkaian Relay yang dapat dilihat pada gambar sebagai berikut :

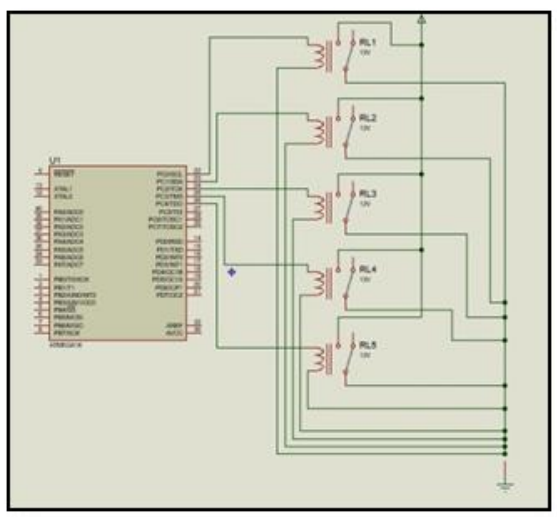

Gambar . Rangkaian Relay

Pada rangkaian diatas menjelaskan rangkaian Relay. Rangkaian ini berfungsi untuk mengatur penjadwalan timer animasi yang sudah dikonfigurasi mikrokontroler atmega 16.

3. Rangkaian LDR ke Mikrokontroler Atmega 16

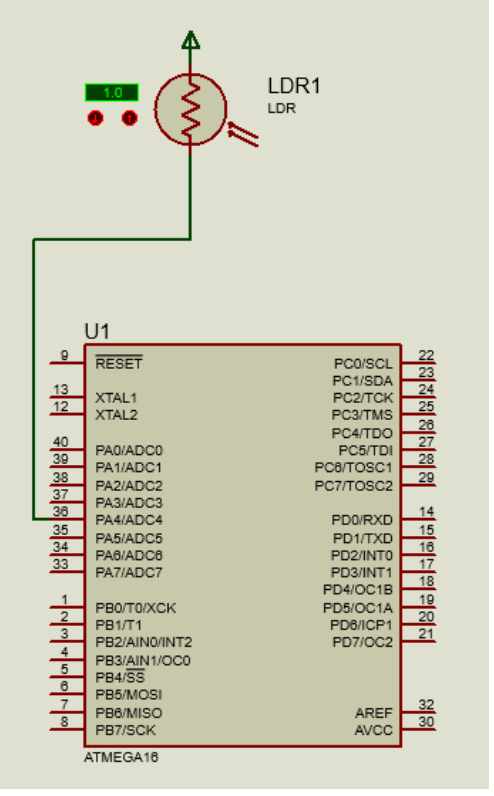

Gambar Rangkaian LDR

Pada rangkaian diatas menjelaskan rangkaian relay. Rangkaian ini berfungsi untuk mendeteksi resistansi.

4. Rangkaian LCD ke Mikrokontroler Atmega 16 


\section{(Jurnal Teknologi Komputer dan Sistem Informasi)}

Februari 2021, Vol 1, No 1, Hlm. 13-18

Available online at http://jurnal.goretanpena.com/index.php/teknisi

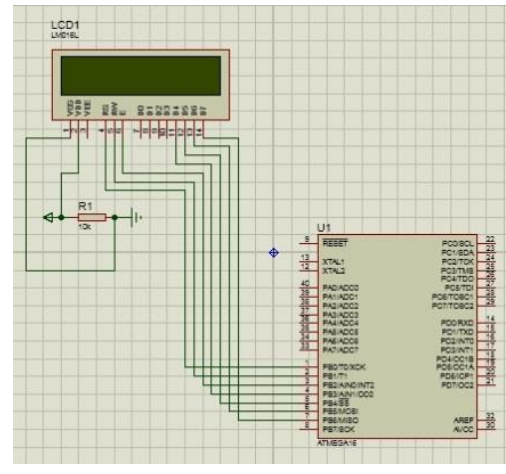

Gambar . Rangkaian LCD

Pada rangkaian diatas penyusunan rangkaian LCD pada mikrokontroler atmega 16. LCD yang digunakan berukuran $16 \quad \mathrm{x} \quad 2$. Pin D4-D7 dihubungkan ke PORTB.4-PORTB.7 mikrokontroler. Pin VDD pada LCD dihubungkan ke resistor yang terhubung pada 5 Volt Mikrokontroler, Pin VSS pada LCD dihubungkan pada resistor yang terhubung pada ground.

5. Rangkaian Keseluruhan

Berikut ini adalah gambar rangkaian keseluruhan dari sistem yang dapat dilihat pada gambar sebagai berikut :

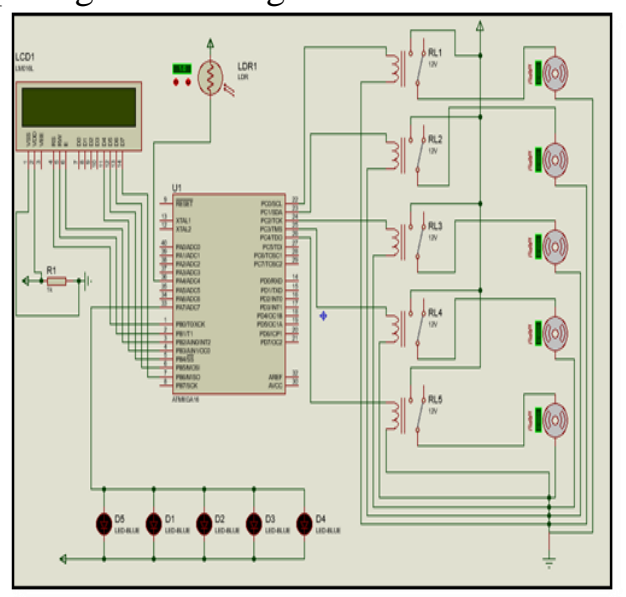

Gambar Rangkaian Keseluruhan Sistem

Pada gambar diatas merupakan rangkaian keseluruhan dari implementasi tenkik counter pada air mancur untuk membuat animasi air berbasis mikrokontroler atmega 16 yang nantinya rangkaian ini dirancang pada rancangan yang sebenarnya

\section{SIMPULAN}

Kesimpulan yang dapat di ambil dari sistem dan rangkaian secara keseluruhan pada Implementasi Teknik Counter Pada air Mancur Untuk Membuat Animasi air Berbasis Mikrokontroler Atmega 16 adalah sebagai berikut :

1. Merancang animasi air mancur otomatis dapat diselesaikan dengan beberapa tahapan penyusunan flowchart sistem, pembuatan gambar rangkaian dan rancang bangun, kemudian dilanjutkan dengan merakit komponen-komponen dan jika komponen sudah terpasang maka selanjutnya membuat penjadwalan animasi air mancur, selanjutnya tahap terakhir membuat program sistem kendali dengan menggunakan software Arduino IDE yang dimasukkan ke dalam mikrokontroler atmega 16.

2. Pada sistem kerja implementasi teknik timer counter pada rancang bangun ini diimplementasikan untuk membuat penjadwalan secara otomatis yang setiap 5 detik akan berganti ke tiap animasi air.

3. Sistem yang dibangun telah diuji coba dan dapat bekerja dengan baik seperti yang diharapkan.

\section{DAFTAR PUSTAKA}

Erikjaya, "Satria Hijau : Defenisi Air Mancur". Erikjaya. 2020, [Online]. Available: http://erikjaya.blogspot.com/2013 /06/definisi-air-mancur.html.

Esparindo, "Air Mancur-Air MancurEsparindo" Esparindo. 2020, [Online]. Available: https://airmancur.com/air-mancur.

Heri Andrianto. (2013), "Pemrograman Mikrokontroler AVR Atmega 16 Menggunakan Bahasa C", Bandung : Informatika Bandung. 
(Jurnal Teknologi Komputer dan Sistem Informasi)

Februari 2021, Vol 1, No 1, Hlm. 13-18

Available online at http://jurnal.goretanpena.com/index.php/teknisi

F. Saputra, "Kinerja Pompa Air DC Berdasarkan Intensitas Tenaga Surya”. 2015, [Online]. Available: http:/eprints.ums.ac.id/36159/27/ 2.NASKAH PUBLIKASI.pdf [Akses : 2020].

Muhamad Saleh, "Rancang Bangun sistem Keamanan Rumah Menggunakan Relay", Vol.8 No.2 Mei 2017.

Lia Kurniawati, "Pengaruh pencahayaan LED (Light Emitting Diode)", No 27, 2008.

Mareta Tri Putri, "Pengendali Lampu
Rumah Otomatis Dengan SMS

Berbasis Mikrokontroler

Atmega8535", No 16, 2014.

Mochamad Iqbal Ardimansyah dan Dadan Nurdin Begenda, "Prototipe Alat

Sortir Bola Berdasarkan Perbedaan Warna Menggunakan LED RGB dan LDR Berbasis Mikrokontroler", Jurnal Ipkia, 65 [Akses : 2020]. 